\title{
Determinants of Market Orientation and Market Participation: Agricultural Commercialization in Central and North Gondar, Ethiopia
}

Tigabu Dagnew Koye ( $\nabla$ tigabu567@gmail.com )

University of Gondar https://orcid.org/0000-0002-5328-345X

Taye Melese Mekie

University of Gondar

Abebe Birara Dessie

University of Gondar

Tegegne Debas Malede

University of Gondar

\section{Research}

Keywords: market orientation, market participation, seemingly unrelated regression, Tobit

Posted Date: November 19th, 2021

DOI: https://doi.org/10.21203/rs.3.rs-1074231/v1

License: (c) (i) This work is licensed under a Creative Commons Attribution 4.0 International License. Read Full License 


\title{
Determinants of Market Orientation and Market Participation: Agricultural Commercialization in Central and North Gondar, Ethiopia
}

\author{
${ }^{1}$ Tigabu Dagnew Koye, ${ }^{1}$ Taye Melese Mekie, ${ }^{1}$ Abebe Birara Dessie and ${ }^{2}$ Tegegne Debas Malede
}

${ }^{1}$ Department of Agricultural Economics

${ }^{2}$ Rural Development and Agricultural Extension

College of Agriculture and Environmental Sciences, University of Gondar, Gondar, Ethiopia; Email: tigabu567@gmail.com, tayemelese20@gmail.com, a.birara@yahoo.com, and tegegnidebas@gmail.com, respectively

\section{Abstract}

In Ethiopia, agricultural transformation is faced with many challenges such as poor infrastructure especially in rural area where huge agricultural activities are carried out, poor institutional services, lack of awareness of farmers on value addition of goods and so on. To fill this knowledge gap, this study was aimed the determinants of market orientation and market participation in Central and North Gondar Rural Ethiopia separately. The data were collected a sample of 344 households selected using multistage purposive and random sampling techniques. Seemingly unrelated regression (SUR) and Tobit regression models were employed. The SUR model estimation indicated adult equivalent, chemical fertilizer users and tropical livestock unit (TLU) affect both market oriented cash and stable crops positively, while child dependency ratio, cultivated land, the distance to the market and road affect both market oriented cash and stable crops negatively. Level of education (grading), and irrigation users affect market oriented cash and stable crops positively, respectively. The empirical results of Tobit model show that cultivated land, land allocated to staples, off/non-farm income and irrigation user affect crop commercialization positively. Based on the findings, the study suggest that farmers should keep going to employ an additional off-farm income activities, improve rural urban roads, employ agricultural intensification, and the government should be supplied chemical fertilizer in sufficient amount and on time at reasonable price to improve farmers ' crop production.

Keywords: market orientation, market participation, seemingly unrelated regression, Tobit 


\section{INTRODUCTION}

Smallholder farmers in Africa have a large share of the arable land; it is not feasible to envisage agricultural transformation without considering them Holden TS and K Otsuka (2014). From the view of most development agencies, research centers, and governments, the transformation targeting increased productivity among smallholders would be the best way to enhance rural income in the short and medium term Larson et al. (2014). Some researchers also argue that transformation of smallholder farmers should be the dominant approach for agricultural led growth in Africa De Janvry and E Sadoulet (2010). Others indicate that improving the production systems of the smallholders as well as their access to markets is becoming a strategy for rural development and poverty reduction Fischer E and M Qaim (2012). Additionally, when focusing on commercialization, smallholder market participation has been recognized as crucial for the transformation to significantly bring the expected growth Jagwe et al. (2010).

In Sub-Sahara Africa (SSA) the majority of the population lives in rural areas where poverty and deprivation is severe. It is estimated that about 70\% of the rural poor in SSA depend on agriculture for their livelihood directly or indirectly (IFAD, 2011). Therefore, agricultural transformation is crucial for poverty reduction and improved food security in sub-Saharan African (SSA) countries, as the agricultural sector is characterized by mainly small-scale, low productivity, low external input usage, and family labor oriented enterprises World Bank (2008: cited in Joachim et al., 2016). Poverty reduction strategies focusing on agriculture directly raise farm incomes by increasing marketable output and indirectly through generating employment as agriculture is labour-intensive. The agricultural sector also has linkages with other sectors such as processing industries and factor markets (Pender and Alemu, 2007).

Ethiopian economy is highly dependent on agricultural activities. Agricultural sector contributes $42.7 \%$ of GDP, providing employment opportunity for $80 \%$ of total population, generates about $70 \%$ of the foreign exchange earnings of the country and supplies over $70 \%$ of raw materials for domestic industries (Zerihun et al., 2015). However, having such great significance in countries' economy, commercialization of agricultural products until recently has been low. Commercialization of agricultural sector is faced with many challenges such as poor infrastructure especially in rural area where huge agricultural activities are carried out, where there are poor institutional services, lack of awareness of farmers on value addition of goods and so on. 
Commercialization in agriculture refers to the progressive shift from household production for auto consumption to production for sale in the market. This shift entails that production and input decisions are based on profit maximization, reinforcing vertical linkages between input and output markets Olwande et al. (2015). Commercializing smallholder agriculture is seen as a means to bring the welfare benefits of market-based exchange economies to this group, and is central to an inclusive development process Arias et al. (2013). Smallholder commercialization is seen as preferable to relying on migration to urban centers where employment growth remains low. Focusing on smallholders also promises to deliver more equitable rural economic growth than commercialization strategies that focus on large farms, with small farms typically employing more labor per unit area compared to large farms, and small-farm household expenditure patterns bring greater benefits to local economies Hazell et al. (2007: cited in Abafita et al., 2016).

Agricultural commercialization refers to the process of increasing the proportion of agricultural production that is sold by farmers (Pradhan et al., 2010). Commercialization of agriculture as a characteristic of agricultural change is more than whether or not a cash crop is present to a certain extent in a production system. It can take many different forms by either occurring on the output side of production with increased marketed surplus or occur on the input side with increased use of purchased inputs. Commercialization is the outcome of a simultaneous decision-making behavior of farm households in production and marketing von Braun et al. (1994: cited in Edward et al., 2102).

Moreover, commercial transformation of subsistence agriculture is a crucial policy choice in economic growth and development for many developing countries like Ethiopia. Agricultural commercialization brings about sustainable food security and welfare and enhances vertical and horizontal market linkages (Birhanu and Moti, 2010). Agricultural commercialization and increased food production is the cornerstone for increasing food security. Smallholder farmers are often good at allocating resources efficiently, therefore those commercializing will contribute largely to economic growth and food security. This will create employment opportunity which eventually enables people to afford nutritious food for a healthy life.

The transformation has generally been considered as shifting from subsistence farming, which is characterized by low productivity to a market-oriented production system Olwande et al. (2015). It is accompanied by using improved inputs, which are designed to lead to higher agricultural production for food self-sufficiency and commercialization. With increased commercialization, agricultural transformation is then seen as an effective way to boost household income and 
stimulate pro-poor growth Diao et al. (2010). In addition, transformation is intended to benefit the rural landless through wage labor creation and food availability.

Increase in market participation by the small householders in Ethiopia is an important means of transforming from the subsistence farming into commercial farming and it is documented in the current development strategy of the country (MoFED and MoARD, 2010). The transition from subsistence to commercial agriculture has long been considered to be a crucial strategy towards agrarian transformation of low income economies and a means of ensuring food security, enhancing nutrition and incomes. The transition from low productivity and semi-subsistence agriculture to high productivity and commercialized agriculture has played a central role in the development of agricultural economics (Zanello, 2011).

To achieve food security, commercial transformation of subsistence agriculture is an indispensable pathway towards economic growth and development for many agriculture dependent developing countries. It is evidenced that policy, technological, organizational and institutional interventions aimed at promoting commercial transformation of subsistence agriculture should improve market orientation of smallholders at production level, and facilitate market entry and participation of households in output and input markets (Birhanu and Moti, 2010). The dynamics and feasibility of smallholder commercialization in improving food security situation is an important policy issue. The commercial behavior of smallholders and the commercialization scale at which they are operating is also a critical research question to be addressed since smallholder commercialization policies are usually designed under such conditions. Various studies on smallholder commercialization generally suggest that there is very low scale of commercialization in Ethiopian agriculture with differentiated factors determining the market orientation and commercialization decisions of rural households (Moti and Gardebroek, 2008; Adane, 2009; Mamo et al., 2009; Bedaso et al., 2012).

The literature on commercialization of smallholders makes clear conceptual distinction between market orientation and market participation of smallholders. As a result, most of the analysis of the determinants of smallholder commercialization is based on the analysis of the determinants of output market participation (Jaleta, et al., 2009 and Otieno et al., 2009). However, analysis of the determinants of market orientation and market participation separately would be useful in guiding the type of interventions needed at production and marketing levels to facilitate commercial transformation. Improvement in market orientation and participation is therefore needed to link 
smallholder farmers to markets so as to have suitable market for agricultural produce as well as to receiving boost for income generation. This paper, therefore, makes the distinction between market orientation and market participation and attempts to analyze the determinants of each separately.

\section{RESEARCH METHDOLOGY}

\subsection{Description of the Study Area}

The study was conducted in Central and North Gondar Districts (Debark from North Gondar; West Belesa and Wogera from Central Gondar). The weather conditions of these Districts are characterized Dega, Woiyna Dega and kola there are mixed farming systems (i.e. livestock rearing and crop productions). The crop production systems are characterized through rain fed and irrigation. According to zone agriculture department, the main staple food includes sorghum, maize and potato. Other food crops include barley, wheat, Teff and pulses. Cash crops like malt barley, lentil, haircot ben and sesame. Onion, tomato, potato and other are some of vegetables produced in irrigation fed (North and central Gondar Zone agriculture office, 2018).

$<$ Figure 1>

\subsection{Data Types, Sources and Methods of Data Collection}

This research was primarily based on primary data through cross-sectional survey during 2018/19 production season. The research was adopted a cross-sectional survey as opposed to longitudinal survey, since the latter requires taking a repeated measurement on continuous bases that have cost and time implications. Hence, it becomes difficult to employ such kind of design in research of this type. However, cross-sectional survey requires one-time data collection and analysis which in turn is time-saving and cost effective (Kothari, 2004). Therefore, this study was design to undertake a cross-sectional survey. The cross-sectional survey was conducted using semi structured questionnaire.

\subsection{Sampling Technique and Sample Size}

Multi stage sampling technique was employed when selecting sample respondents. Central Gondar and North Gondar administrative zones of Amhara Region were selected purposively from the two agro ecology. Since two agro ecologies are expected for their heterogeneity in terms of their commercialization situations, two-stage stratified random sampling technique was employed. In the first stage of sampling, districts will be stratified according to their agro-ecology such as highland and mid attitude. To obtain representative sample households from the agro ecology, two districts West Belesa and Wogera from Central Gondar and Debark from North Gondar were selected purposively. In the second stage, five Kebele Administrations (KAs) in West Belesa and; four KAs 
from Wogera and Debark (total eight KAs) was randomly selected. Finally, a total of 344 rural households were randomly sampled from $13 \mathrm{KAs}$ proportionate to the number of households in each District.

\subsection{Methods of Data Analysis}

Descriptive statistics (percent and mean) and econometric analysis were used to analyze data.

\section{Market Orientation and Commercialization}

\section{Market orientation index (MOI)}

The household's decisions as to which crop, categories to produce are assumed to be interdependent. The decision to produce one type of crop is at the expense of production of the other crop for the fact that resources, particularly land, labor and capital, are limited. We define that a smallholder is market oriented if its production plan follows market signals and produce commodities that are more marketable. Under a semi-commercial system, where both market and home consumption are playing a central role in production decision, all crops produced by a household may not be marketable in the same proportion. Thus, households could differ in their market orientation depending on their resource allocation (land, labor and capital) to the more marketable commodities. Marketability of cereal crops will be computed at the district level since districts are the closest representatives of the farming systems included in the study. Hence, based on the proportion of total amount sold to total production at district level, a crop specific marketability index $\left(\alpha_{k}\right)$ is computed for each crop produced at district level as follow

$$
\alpha_{k}=\frac{\sum_{i}^{N} S_{k}}{\sum Q_{k i}} \quad Q_{k i}>S_{k} \quad 0 \leq \alpha_{k} \leq 1
$$

Where $\alpha_{k}$ is the proportion of crop $k$ sold $\left(S_{k i}\right)$ to the total amount produced $\left(Q_{k i}\right)$ aggregated over the total sample households in a district. $\alpha_{k}$ takes a value between 0 and 1, inclusive. Crops mainly produced for markets usually have $\alpha_{k}$ values closer to 1 . Once the crop specific marketability index is computed, household's market orientation index in land allocation $\left(M O I_{i}\right)$ is computed from the land allocation pattern of the household weighted by the marketability index of each crop $\left(\alpha_{k}\right)$ derived from the above as follows.

$$
\text { MOI }_{\mathrm{i}}=\frac{\sum_{\mathrm{k}=1}^{\mathrm{k}}\left(\alpha_{\mathrm{k}} \mathrm{L}_{\mathrm{ik}}\right)}{\mathrm{L}_{\mathrm{i}}^{\mathrm{T}}} \quad \mathrm{L}_{\mathrm{i}}^{\mathrm{T}}>0 \quad 0<\mathrm{MOI}_{\mathrm{i}} \leq 1
$$

Where MOI is market orientation index of household $\mathrm{i}, L_{i k}$ is amount of land allocated to crop $\mathrm{k}$, and $\mathrm{Li}$ is the total crop land operated by household $\mathrm{i}$. The higher proportion of land a household allocates to the more marketable crops, the more the household is market oriented. The equation for 
households' market orientation scale between staples and cash crops will be assumed to have some correlation. To account for this, the equations for households' market orientation of staples and cash crops will be estimated by a two equation Seemingly Unrelated Regression (SUR) model.

moist $_{\mathrm{i}}=\mathrm{X}_{1} \beta_{1}+\varepsilon_{\mathrm{i} 1}$

moic $_{\mathrm{i}}=\mathrm{X}_{2} \beta_{2}+\varepsilon_{\mathrm{i} 2}$

Where: moist and moic are market orientation scales of staples and cash crops of households, respectively.

\section{Tobit Regression Model}

The determinants of the level of market participation were estimated using the tobit model. The model is explicitly expressed as:

$$
\mathrm{Z}_{\mathrm{i}}=\alpha_{0}+\alpha_{\mathrm{i}} \mathrm{S}_{\mathrm{i}}+\varepsilon_{\mathrm{i}}
$$

Where: $Z_{i}=$ sales volume in percentage; $\alpha_{0}=$ intercept; $\alpha_{i}=$ parameters; $S_{i}=$ Variables that determine market participation, and $\varepsilon_{\mathrm{i}}=$ error term

\section{RESULTS AND DISCUSSION}

\subsection{Market orientation estimation using SUR model}

Table 1 below presents coefficient estimates of Seemingly Unrelated Regression (SUR) model for households' market orientation. This study tested the null hypothesis that error terms for households' market orientation are not related. The Breusch-Pagan test rejects the null hypothesis of independence between market orientation index of cash crops and market orientation index of stables crops residual series at the $1 \%$ level of significance. The test empirically confirms that it is appropriate to estimate the simultaneous equations of market orientation index of cash crops and market orientation index of stables crops using the SUR model.

\section{$<$ Table 1>}

Child dependency ratio detracts from household market orientation both market orientation indexes of cash and stables crops due to its effect on increasing household domestic consumption needs, as expected. A higher dependency ratio is likely to reduce productivity growth. A growth in the nonproductive population will diminish productive capacity and could lead to a lesser both market orientation indexes of cash and stables crops. As proportions of child dependency ratio increased by $1 \%$, market oriented on cash and stables crops declined by $0.15 \%$ and $0.11 \%$, respectively.

Family size (adult equivalent): Labor availability was found to be positive and significant effect on both market orientation indexes of cash and stables crops. This indicates that large labor availability 
supplies more labor that can be well utilized in a relatively better price. As active labor force increases by $1 \%$, market orientation indexes of cash and stables crops increases by $8.34 \%$ and $5.21 \%$, respectively.

For the improvements in farm household agricultural commercialization, the role of farm technologies, like the use of fertilizer, play an important role. The use of fertilizer adoption was both market orientation indexes of cash and stables crops than non-users. It is positive and statistically significant on both market orientation indexes of cash and stables crops at $1 \%$ probability level. The role of fertilizer adoption was facilitating rural transformation as higher production into surplus products and greater ability to integrate with the output market. As hypothesized, if the use of fertilizer adoption of farm household increased by $1 \%$ unit, market oriented on cash and stables crops found to be increased by $56.69 \%$ and $45.05 \%$ units, respectively. Thus, fertilizer adopters are enhancing on both market orientation indexes of cash and stables crops than non-users.

The estimated coefficient associated with livestock holding (TLU) is positive and statistically significant on both market orientation indexes of cash and stables crops at $10 \%$ and $5 \%$ probability level, respectively. Households who have more livestock holding may not have difficulties to purchase inputs like seed, fertilizer and the like and also oxen ownership is among the livestock units considered which help farmers in land preparation and sowing. More livestock ownership also supplies more organic fertilizer to improve both market oriented on cash and stables crops. As the value of livestock holding by the farm household increased by $1 \%$, market oriented on cash and stables crops increased by $4.52 \%$ and $4.67 \%$ units, respectively. Thus, increase in livestock holding results in an increase on both market orientation indexes of cash and stables crops.

Irrigation users had a positive and significant effect on market orientated on stables crops at $10 \%$, and more market orientated on stables crops than non-users; because irrigation user farmers benefit the returns on land and labour are increased, nutrition is improved, and consumption is stabilized as the lean periods are eliminated or reduced. Its benefit is higher yields; higher cropping intensity and all year round farm production leads to increased marketable surplus production and perhaps food security. As hypothesized, if the use of irrigation of farm household increased by $1 \%$ unit, market oriented on stables crop found to be increased by $15.89 \%$ units.

The educational level of farmers had a positive and significant effect on market orientation index of cash crops at 5\% significant level. As a household head level of education increases by one year of 
schooling, the household increases market orientation index of cash crops by $3.62 \%$. This implies that as the educational level of the farmers increases, their ability to get information on how to produce and sell more at the sound market price.

The distance to market and road indicated negatively affect on both market orientation indexes of cash and stables crops. It shows that by maintaining other variables constant when the number of a kilometer to the market increases by one $\mathrm{km}$, the household market orientation index of cash and staples crops declined by $1.23 \%$ and $0.95 \%$, respectively; and also it shows that by maintaining other variables constant when the number of a kilometer to the road increases by one $\mathrm{km}$, the household market orientation index of cash and staples crops declined by $0.57 \%$ and $0.51 \%$, respectively.

Land cultivated is one of the most important factors of production on which different farm activities were carried out. Land cultivated negatively affect on both market orientation indexes of cash and stables crops, and statistically significant at $10 \%$ and 5\%, respectively. As land cultivated increases by 1.0 ha, market orientation indexes of cash and stables crops decreases by $11.59 \%$ and $13.97 \%$, respectively. Thus, farmers might not be expand the land cultivated (mean land cultivated was 1.5 ha) for production.

\subsection{The determinants of crop commercialization}

As shown in Table 2, the likelihood function of the Tobit model for crop commercialization index is highly significant $\left(\mathrm{LR} \mathrm{Chi}^{2}(25)=95.72\right.$ with $\left.\mathrm{Prob}>\mathrm{Chi}^{2}=0.0000\right)$ indicating a strong explanatory powers of the independent variables. Out of the 25 explanatory variables included in the model, four variables, namely land cultivated, land allocated to staples, irrigation use and annual total gross income were found to significantly influence the crop commercialization.

Land allocated to staples had a positive and significant influence on the level of crop commercialization at $10 \%$ probability level of significance. The marginal effect result indicated that as the land allocated to staples by the household increased by one hectare, the decision to participate in crop commercialization would be increased by $2 \%$.

The irrigation user for crop commercialization decision is positively and the effect is statistically significant at $1 \%$. It can lead to a reduction in crop production risk and, therefore, provides greater incentives to increase input use, increase crop yields, intensify crop production and diversify into higher-valued crops. The resulting increase in marketable surplus and commercial activities has the 
potential to generate increased incomes for farmers. The marginal effect also confirms that the irrigation user increases crop commercialization by $758 \%$, all other factors held constant.

<Table 2>

Coefficient of land cultivated was positive and statistically significant on crop commercialization at $1 \%$ probability level. This could be attributed to the fact that a larger area of arable land provides a greater opportunity to produce surplus which require sales. The marginal effect result also indicated that as the land cultivated by the household increased by one hectare, the decision to participate in crop commercialization would be increased by $416 \%$. The more the land cultivated, farmers more participated in crop commercialization.

The coefficient off-farm income was a positive and statistically significant on crop commercialization at $10 \%$ probability level. This is attributed to the fact that off-farm income provides extra capital that is invested in farming in the form of purchasing inputs and hiring labor. Hence, farmers with such earnings reflect higher crop commercialization. The marginal effect result indicated that as the sum of off-farm income of the household increased by one birr the decision to participate in crop commercialization would be increased by $0.03 \%$. This indicates that income from other sources such as trading, wages among others is utilized on the farm to boost production, and to participate in crop commercialization.

\subsection{Measure of Commercialization among Respondents}

The values of crops produced during the previous cropping season and the amount received for crops sold by respondents was used to determine the commercialization index as shown in Table 3.

$<$ Table 3>

The mean HCI calculated among the farmers in the study area is 0.23 , with a minimum value of 0 , a maximum value of 1 , and standard deviation of 0.24 . The data indicate that on the commercialization continuum stretching from subsistent to fully commercialized (0-1); many farmers in the study area are situated below the halfway mark at 0.23 . Some farmers from the data observed are at 1 while others are at 0 , located on the extremes of the commercialization continuum.

\subsection{Commercialization Classification Index}

The household commercialization index was used to determine the position of respondents on a commercialization continuum. The continuum was divided into four percentiles and farmers were classified accordingly, as indicated in Figure 2. 
As seen from Figure 2, more than $50 \%$ of the target population falls into the first percentile of the commercialization index class. Approximately $21.5 \%$ of the farmers are in the third percentile of the commercialization index class, and $17.2 \%$ of the farmers fall into the second percentile of the commercialization index class. However, close to $2 \%$ of the respondents fall in the top percentile of the commercialization index class.

$<$ Figure 2>

\section{CONCLUSION AND RECOMMENDATION}

This study aimed to analyze the determinants of market orientation and market participation in Central and North Gondar Rural Ethiopia separately. This study used primary data collected from 344 sampled household through semi-structured questionnaire. The SUR model estimation indicated that adult equivalent, fertilizer users and TLU affect both market oriented on cash crops and market oriented on stables crops, while child dependency ratio, land cultivated, the distance to the market and road affect both market oriented on cash crops and market oriented on stables crops negatively. Level of education and irrigation users affect market oriented on cash crops and market oriented on stables crops positively, respectively. The Tobit model estimation indicated that land cultivated, land allocated to staples, irrigation users and off-farm income positively affect crop commercialization.

Education level of the household should up-grade primarily adult education, and building the skill of the household that develop their ability is vital for market orientation.

Farmers should keep going to employ in additional off-farm income activities for greater level of crop commercialization.

The government should improve rural urban roads in the district as access to village town for market orientation development.

Child dependency ratio influences market orientation negatively. Farmers with more children (Child dependency ratio) tend to less contribute in market orientation. Therefore, the government is supposed to work strongly on family planning strategy to rural farm households by health extension workers at kebele level.

Land cultivated is negatively affect market oriented on cash crops. So, the farmers must be use agricultural intensification derived from production packages like agronomic practices and proper application of inputs. 
Irrigation users were positively affecting crop commercialization. So, the irrigation administrators should be given more emphasis so as to improve the irrigation development performance for crop commercialization.

For the improvement of market orientation, the government should be supplied chemical fertilizer in sufficient amount and on time at reasonable price to improve farmers' crop production.

\section{Acknowledgements}

We presented thanks to the University of Gondar for funding and West Belesa, Wogera and Debark Districts for facilitating data collections and providing data; the farmers who provided the primary data.

\section{Authors' contributions}

All authors read and approved the final manuscript.

\section{Funding}

This work was supported by the University

\section{Availability of data and materials}

All authors declare that the data sets used in this manuscript are fully available upon request from the corresponding author.

\section{Competing interests}

The authors declare that they have no competing interests.

\section{REFERENCES}

Abafita, J., Atkinson, J. and Kim, C.-S., 2016. Smallholder Commercialization in Ethiopia: Market Orientation and Participation. International Food Research Journal 23(4): 1797-1807 (2016). http://www.ifrj.upm.edu.my

Adane Tufa, 2009. Impact of Perennial Cash Cropping on Food Crop Production and Productivity; Ethiopian Journal of Economics 18(1): 1-34

Arias, P., Hallam, D., Krivonos, E. and Morrison, J., 2013. Smallholder integration in changing food markets; Food and Agriculture Organization of the United Nations, Rome

Bedaso Taye, Wondwosen Tsegaye and Mesfin Ketema, 2012. Commercialization of Ethiopian smallholder farmers' production: factors and challenges behind. Paper presented on the Tenth International Conference on the Ethiopian Economy, Ethiopian Economics Association, July 19-21, 2012, Addis Ababa, Ethiopia 
Birhanu Gebremedhin and Moti Jaleta, 2010. Commercialization of smallholders: Does market orientation translate into market participation? ILRI (International Livestock Research Institute), Addis Ababa, Ethiopia.

De Janvry A and E Sadoulet, 2010. Agriculture for development in sub-Saharan Africa: An update. AFJARE; 5(1):194-204.

Diao X, Hazell P and J Thurlow, 2010. The Role of Agriculture in African Development

Edward Martey, Ramatu M. Al-Hassan and John K. M. Kuwornu, 2012. Commercialization of smallholder agriculture in Ghana: A Tobit regression analysis. African Journal of Agricultural Research Vol. 7(14), pp. 2131-2141. http://www.academicjournals.org/AJAR

Fischer E and M Qaim, 2012. Gender, agricultural commercialization, and collective action in Kenya; Food Security; 4: 441-453

Holden TS and K Otsuka, 2014. The roles of land tenure reforms and land markets in the context of population growth and land use intensification in Africa. Food Policy; 48:88-97

IFAD, 2011. Rural poverty report; International Fund for Agricultural Development

Jagwe J, Matchethe C and E Ouma, 2010. Transaction costs and smallholder farmers' participation in banana markets in the Great Lakes Region of Burundi, Rwanda and the Democratic Republic of Congo; AFJARE; 6 (1):302-317.

Jaleta, M., B. Gebremedhin, and D. Hoekstra, 2009. Smallholder Commercialization: Processes, Determinants and Impact. Discussion Paper No. 18. Improving Productivity and Market Success (IPMS) of Ethiopian Farmers Project; ILKRI, Nairobi, Kenya. 55pp.

Joachim Vandercasteelen, Seneshaw Tamru, Bart Minten, and Johan Swinnen, 2016. Cities and agricultural transformation in Africa: Evidence from Ethiopia. Facilitated by the International Food Policy Research Institute (IFPRI), The Ethiopia Strategy Support Program (ESSP) works closely with the government of Ethiopia, the Ethiopian Development Research Institute (EDRI). http://www.edri-eth.org/.

Larson DF, Otsuka K, Matsumoto T and T Kilic, 2014. Should African rural development strategies depend on smallholder farms? An exploration of the inverse-productivity hypothesis.; Agricultural Economics; 45:355-367.

Mamo Girma, Assefa Admassie, and Degnet Abebaw, 2009. Determinants of smallholder crop farmers' decision to sell and for whom to sell: Micro level data evidence from Ethiopia. In: Getnet Alemu and Worku Gebeyehu (eds), Proceedings of the Ninth International Conference on the Ethiopian Economy, PP 47-76, Addis Ababa, Ethiopia. 
MoFED and MoARD, 2010. Global agriculture and food security programme: FYGTP (FiveYear Growth and Transformation Plan). Addis Ababa, Ethiopia. 41p.

Moti Jaleta and C. Gardebroek, 2008. Crop and market outlet choice interactions at household level; Ethiopian Journal of Economics, 7(1): 2947.

North and Central Gondar Zone Agricultural Office, 2018. Socio-economic profile description of Central and North districts of Northwestern, Gondar, Ethiopia

Olwande, J., Smale, M., Mathenge, M. K., Place, F. and Mithöfer, D.2015. Agricultural marketing by smallholders in Kenya: A comparison of maize, kale and dairy. Food Policy 52: 22-32.

Otieno, D.J., J. Omiti, T. Nyanamba, and E. McCullough, 2009. "Market Participation by Vegetable Farmers in Kenya: A comparison of Rural and Peri-urban Areas." African Journal of agricultural Research, Vol 4(5): 451-460.

Pender, J. and Dawit, Alemu, 2007. Determinants of Smallholder Commercialization of Food Crops: Theory and Evidence from Ethiopia. Discussion Paper No. 75. IFPRI (International Food Policy Research Institute), Washington, DC, USA.

Zanello, G., 2011. Does the use of mobile phones reduce transactions costs and enhance participation in agricultural markets? Household evidence from Northern Ghana; Paper presented CSAE Conference, March 20 2011. 23p.

Zerihun M, Mulatu F, and Breitenbach M, 2015. Assessment of monetary union in SADC: Evidence from Co integration and panel unit root tests Paper submitted to: $13^{\text {th }}$ International Conference on the Ethiopian Economy: July 16-19, 2015. Addis Ababa, Ethiopia 
Figures



Figure 1

Map of the study areas 


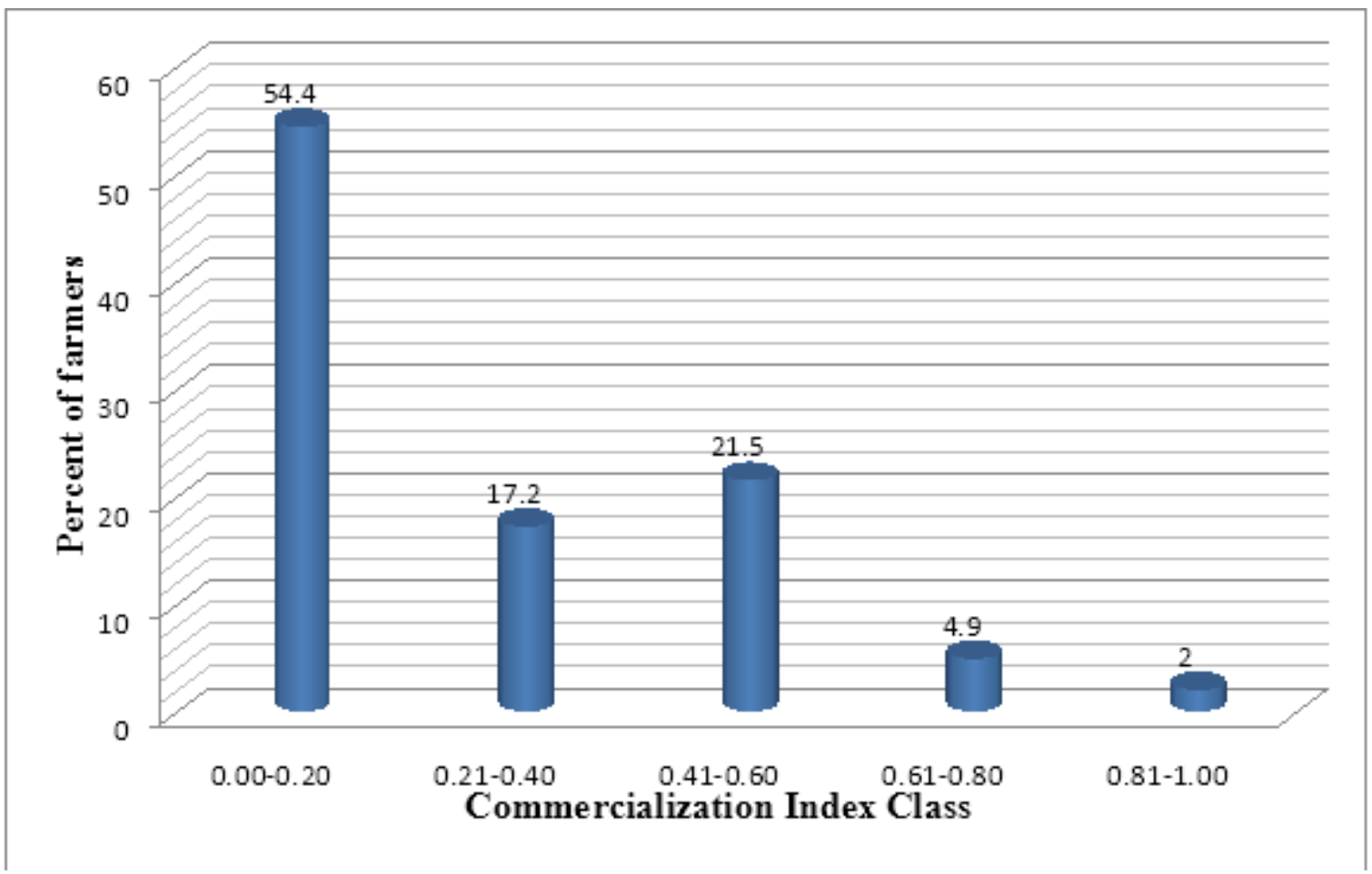

Figure 2

Commercialization Classification Index of Respondents $(\mathrm{N}=344)$ Source: Computed from Field Survey Data, 2019/20 